\title{
Peningkatan Produktifitas UKM Produk Sugarwax melalui Intervensi Ergonomi di Stasiun Kerja
}

\author{
Lamto Widodo $^{1}$, Silvi Ariyanti ${ }^{2}$, Jesselyn Octavia ${ }^{3}$ \\ ${ }^{1,3)}$ Fakultas Teknik, Program Studi Teknik Industri, Universitas Tarumanagara Jakarta \\ Jl. Letjen S. Parman No.1 Jakarta Barat 11440 \\ E-mail: lamtow@ft.untar.ac.id \\ ${ }^{2)}$ Fakultas Teknik, Jurusan Teknik Industri, Universitas Mercubuana Jakarta \\ Jl. Meruya Selatan No.1 Jakarta Barat 11650
}

\begin{abstract}
ABSTRAK
UKM sugarwax merupakan Usaha Kecil dan Menengah yang bergerak di bidang usaha perawatan kecantikan. Produksi industri ini adalah gel waxing untuk wanita dengan menggunakan bahan dasar gula yang dicairkan sebagai media mencabut bulu. Penelitian awal menemukan ketidaknaturalan postur tubuh pekerja. Kondisi ini menyebabkan keluhan pekerja, khusunya keluhan muskuloskeletal. Tujuan penelitian adalah mengetahui faktor penyebab keluhan musculoskeletal, tingkat risiko ergonomi, serta untuk mendapatkan rancangan stasiun kerja dan alat bantu kerja yang ergonomis. Dari kuesioner NBM (Nordic Body Map) ditemukan keluhan sakit pada leher, bahu atas, pinggang dan kaki. Aktivitas pada proses pengemasan memiliki level risiko WERA (Workplace Ergonomic Risk Assessment) dan REBA (Rapid Entire Body Assessment) tertinggi. Tahap selanjutnya, dilakukan perancangan alat bantu dengan menggunakan metode Analytical Hierarchy Process (AHP). Rancangan ini diimplementasikan, dan menunjukkan skor WERA tertinggi menurun dari 47 (risiko tinggi) menjadi 27 (risiko rendah). Demikian juga skor REBA tertinggi menurun dari 11 (sangat tinggi) menjadi 5 (medium). Terjadi penurunan keluhan sakit sebesar 54\%. Waktu baku aktivitas mengalami penurunan sebesar 40,85\% (dari 49,249 detik menjadi 29,131 detik). Produktifitas seorang pekerja meningkat $24,2 \%$ (dari 33 menjadi 41 buah) yang telah siap kirim per jamnya. Penelitian lanjutan diperlukan untuk mengetahui faktor-faktor ergonomi lain yang mempengaruhi sistem kerja, misalnya factor lingkungan kerja dan faktor sosial.
\end{abstract}

Kata Kunci: Ergonomi, Alat Bantu Kerja, WERA, REBA, produktifitas

\begin{abstract}
Sugarwax is a small-mdium enterprise, engaged in business of the beauty-care. The production is waxing gel for women, using the basic ingredients of sugar which is melted as a medium for plucking feathers. Early research found the abnormality of worker posture. This condition causes complaints of workers, especially musculoskeletal complaints. The research objective was to determine the factors that cause musculoskeletal complaints, the level of ergonomic risk, and to propose the design of work stations and ergonomic work tools. From the Nordic Body Map (NBM) questionnaire, complaints of pain in the neck, upper shoulders, waist and legs were found. Activities in the packaging process have the highest Workplace Ergonomic Risk Assessment (WERA) and Rapid Entire Body Assessment (REBA) levels. The next step, the design of the tools was carried out using the Analytical Hierarchy Process (AHP) method. This design was implemented, and showed the highest WERA score decreased from 47 (high risk) to 27 (low risk). Likewise, the highest REBA score decreased from 11 (very high) to 5 (medium). There was a 54\% decrease in pain complaints. The standard time has decreased by $40.85 \%$ (from 49.249 seconds to 29.131 seconds). The productivity of a worker increases by $24.2 \%$ (from 33 to 41 pieces) which is ready to send per hour. Further research is needed to find out other ergonomic factors that affect the work system, including work environment, economic and social factors.
\end{abstract}

Keywords: Ergonomic, Work Tools, WERA, REBA, and Nordic Body Map (NBM) 


\section{Pendahuluan}

Perkembangan perekonomian Indonesia tidak terlepas dari peran Usaha Kecil dan Menengah (UKM) yang menjadi tulang punggung perekonomian bangsa. Kementerian Koperasi dan UKM [1] mencatat kontribusi sektor Usaha Mikro, Kecil, dan Menengah (UMKM) terhadap produk domestik bruto (PDB) Indonesia meningkat dari 57,84 persen menjadi 60,34 persen pada tahun 2013. Melihat besarnya sumbangan yang diberikan UKM dalam menjaga ketahanan dan meningkatkan perekonomian Indonesia, salah satu cara memperkuat sektor UKM adalah dengan menciptakan iklim usaha yang kondusif bagi UKM, yaitu dengan melakukan pengembangan dalam bidang produksi dan pengolahan [2]. Menurut Shinde and Jadhav [3], pengembangan dalam bidang produksi dan pengolahan dengan melakukan perbaikan ergonomi di tempat kerja menghemat lebih banyak biaya dibanding menginvestasikan modal pada manusia, mesin, material, dan metode (4M). UKM sugarwax merupakan Usaha Kecil dan Menengah yang bergerak di bidang usaha perawatan kecantikan. Produksi industri ini adalah gel waxing untuk wanita dengan menggunakan bahan dasar gula yang dicairkan sebagai media mencabut bulu. Baik pada proses produksi maupun pengemasan pada UKM sugarwax, hampir keseluruhan aktivitas dilakukan secara manual, dimana sistem kerja yang ada belum tertata dengan rapi dan menerapkan prinsip ergonomic. Masih ditemukannya ketidakwajaran postur tubuh pekerja saat melakukan aktivitasnya, diantaranya yaitu postur berjongkok, postur membungkuk lebih dari 60 derajat, dan postur memutar (twist). Kondisi kerja ini terkait erat dengan persoalan keamanan, kenyamanan dan keselamatan kerja, atau persoalan ergonomi.

Terdapat hubungan yang kuat antara ergonomi dengan perancangan sistem kerja. Sehingga perancangan sistem kerja yang memperhatikan kaidah ergonomi dapat meningkatkan output dan performansi pekerja, serta meningkatkan kualitas dan produktivitas sistem [4]. Bekerja pada kondisi yang tidak ergonomis dapat menyebabkan terjadinya gangguan muskuloskeletal, seperti nyeri otot pada pinggang, punggung, dan leher. Berdasarkan penelitian awal melalui kuesioner Nordic Body Map yang dibagikan kepada dua orang pekerja di bagian produksi, keluhan tersebut sering muncul pada bagian tubuh bahu kanan (100\%), lengan atas kanan (100\%), pinggang (100\%), dan betis kanan (100\%). Kuesioner juga dibagikan kepada empat orang pekerja di bagian pengemasan, keluhan yang sering muncul pada bagian tubuh leher atas (100\%), bahu kanan (100\%), pinggang (100\%), lengan atas kanan (100\%), lengan atas kiri $(75 \%)$, bahu kiri $(75 \%)$, pinggang bawah $(75 \%)$, punggung $(25 \%)$, paha kanan $(25 \%)$, betis kanan $(25 \%)$, dan pergelangan kaki kanan $(25 \%)$.

Berdasarkan uraian latar belakang di atas, maka permasalahan pokok dalam penelitian ini dapat dirumuskan bahwa sistem kerja serta aktivitas pada UKM sugarwax belum menerapkan kaidah-kaidah ergonomi yang menyebabkan timbulnya risiko ergonomi serta keluhan muskuloskeletal dalam bekerja. Oleh karena itu, penelitian ini bertujuan untuk memperoleh pemahaman apakah sistem kerja yang diterapkan telah memenuhi kaidah ergonomi serta mengetahui gambaran tingkat risiko ergonomi dan keluhan fisik yang dialami oleh pekerja; memahami faktor penyebab timbulnya keluhan muskuloskeletal serta risiko dalam bekerja berkaitan dengan aspek postur pekerja, stasiun kerja, dan fasilitas yang digunakan; mendapatkan rancangan mengetahui perubahan postur pekerja, keluhan sistem muskuloskeletal dan tingkat risiko ergonomi setelah adanya implementasi perbaikan stasiun dan alat bantu kerja sesuai dengan prinsip ergonomi.

Ergonomi adalah disiplin ilmu yang mencakup pengetahuan tentang intarksi antara manusia dan elemen system lain, dan profesi yang mengaplikasikan teori, prinsip, data dan metode perancangan dengan tujuan untuk optimisasi kesejahteraan manusia dan kinerja system secara keseluruhan (IEA)[5]. Penerapan ergonomi sejalan dengan ilmu rekayasa yang bertujuan untuk mencapai kesesuaian antara manusia dan pekerjaannya demi mencapai kesejahteraan (ILO)[6]. Dalam merancang sebuah fasilitas kerja yang ergonomis, pengetahuan tentang dimensi tubuh sangat penting bagi perancang peralatan dan tempat kerja yang melibatkan deskripsi dari dimensi ukuran dan bentuk tubuh manusia, yaitu antropometri. Antropometri adalah ilmu pengukuran dan seni pengaplikasian yang membentuk geometri fisik, mass properties, dan kemampuan kekuatan tubuh manusia (Singh, dkk)[7]. Tujuan utama dari perancangan fasilitas kerja yang ergonomis adalah untuk mengurangi keluhan sakit akibat kerja. Salah satu cara untuk mengetahui hal tersebut adalah melalui Nordic Musculoskeletal Questionnaire (NMQ, Kourinka. dkk.) [8]. NMQ bertujuan untuk mengetahui bagian-bagian tubuh pekerja yang mengalami keluhan dengan tingkat keluhan mulai dari rasa tidak sakit sampai sangat sakit, baik pada saat sebelum dan sesudah melakukan pekerjaan sehingga kuesioner ini dapat digunakan untuk membuat suatu rancangan agar keluhan yang pekerja terima dapat segera hilang. Kemudian dari NMQ tersebut dikembangkanlah kuesioner Nordic Body Map (NBM). 
Selain menggunakan kuesioner NBM, keluhan yang dirasakan pekerja dapat diukur tingkat risiko ergonominya dengan Workplace Ergonomic Risk Assessment (WERA) dan Rapid Entire Body Assessment (REBA) terkait dengan kelelahan kerja muskuloskeletal (WMSDs) akibat postur tidak natural saat bekerja. Penilaian kategori WERA (Abd. Rahman) [9], dibagi ke dalam tiga kategori hasil yaitu: rendah (skor 1827: pekerjaan dapat diterima), sedang (skor 28-44: pekerjaan perlu investigasi lanjut dan membutuhkan perbaikan), dan tinggi (skor 45-54: pekerjaan yang diamati tidak dapat diterima, perlu melakukan perbaikan segera). Sedangkan penilaian dengan kategori REBA menurut Hignet dan McAtamney [10] dibagi ke dalam lima kategori hasil yang dapat dilihat pada Tabel 1 .

Tabel 1. Level Tindakan REBA

\begin{tabular}{|c|c|c|c|}
\hline $\begin{array}{c}\text { Skor } \\
\text { REBA }\end{array}$ & $\begin{array}{l}\text { Level } \\
\text { Risiko }\end{array}$ & $\begin{array}{l}\text { Action } \\
\text { Level }\end{array}$ & Tindakan \\
\hline 1 & $\begin{array}{c}\text { Dapat } \\
\text { diabaikan }\end{array}$ & 0 & Tidak perlu perbaikan \\
\hline $2-3$ & Rendah & 1 & $\begin{array}{c}\text { Perubahan mungkin } \\
\text { dibutuhkan }\end{array}$ \\
\hline $4-7$ & Medium & 2 & $\begin{array}{c}\text { Investigasi lebih lanjut, perlu } \\
\text { perbaikan }\end{array}$ \\
\hline $8-10$ & Tinggi & 3 & Investigasi, perbaikan segera \\
\hline $11-15$ & $\begin{array}{l}\text { Sangat } \\
\text { tinggi }\end{array}$ & 4 & Perbaikan langsung \\
\hline
\end{tabular}

Setelah mengetahui adanya keluhan sakit melalui kuesioner NBM serta mengetahui tingkat risiko ergonomi pada aktivitas kerja yang diamati, dilakukan analisis keluhan, harapan dan kebutuhan dari wawancara dengan pekerja sehingga didapatkan alternatif-alternatif desain stasiun kerja dan alat bantu untuk aktivitas yang memiliki risiko tertinggi. Alternatif desain dihasilkan dengan mempertimbangkan ukuran antropometri pekerja, peta tangan kiri dan tangan kanan, dan prinsip ergonomi. Alternatif desain akan dipilih dengan menggunakan metode Analytical Hierarchy Process (AHP). Menurut Saaty [11], AHP mempunyai kemampuan untuk memecahkan masalah yang multi objektif dan multi-kriteria yang berdasarkan pada perbandingan preferensi dari setiap elemen dalam hirarki.Melalui AHP, akan diperoleh alternatif desain terbaik untuk kemudian dilakukan simulasi dengan perangkat lunak CATIA. Software CATIA sebagai simulasi untuk menampilkan gerakan yang dilakukan manusia dalam penggunaan alat bantu kerja.

\section{Metode Penelitian}

Penelitian dilakukan pada UKM yang menghasilkan produk perawatan kecantikan sugarwax pada tanggal 1 Agustus 2017 dimulai dengan melakukan wawancara awal kepada pekerja, pengamatan langsung kondisi kerja, studi pustaka serta membagikan kuesioner NBM untuk mengetahui keluhan operator. Selanjutnya dilakukan analisis postur kerja dengan metode WERA dan REBA untuk mengetahui tingkat risiko ergonomi. Data lain yang diamati adalah waktu proses dan produktivitas kerja. Tahap selanjutnya dilakukan perancangan ulang alat bantu kerja berupa alternatif-alternatif desain. Kemudian dipilih alternatif optimal dengan menggunakan metode AHP. Pada tahap terakhir dilakukan implementasi perancangan perbaikan dan analisis hasil implementasi berupa keluhan muskuloskeletal, tingkat risiko ergonomi dengan parameter WERA dan REBA, pengukuran waktu proses dan produtivitas kerja.

\section{Hasil Dan Pembahasan}

\section{Analisis Kuesioner NBM, WERA dan REBA}

Rekap hasil dari kuesioner NBM, WERA dan REBA, diurutkan mulai level risiko tertinggi hingga level risiko terendah dapat dilihat pada Tabel 2 berikut ini. 
Tabel 2. Perbandingan hasil NBM, WERA dan REBA bagian produksi dan pengemasan

\begin{tabular}{|c|c|c|c|c|c|c|c|}
\hline \multicolumn{4}{|c|}{ Bagian Produksi } & \multicolumn{4}{|c|}{ Bagian Pengemasan } \\
\hline Aktivitas & $\begin{array}{c}\text { Skor } \\
\text { WERA }\end{array}$ & $\begin{array}{c}\text { Skor } \\
\text { REBA }\end{array}$ & $\begin{array}{c}\text { Kuesioner } \\
\text { Nordic Body } \\
\text { Map }\end{array}$ & $\begin{array}{c}\text { Kuesioner } \\
\text { Nordic Body } \\
\text { Map }\end{array}$ & $\begin{array}{c}\text { Skor } \\
\text { WERA }\end{array}$ & $\begin{array}{c}\text { Skor } \\
\text { REBA }\end{array}$ & Aktivitas \\
\hline $\begin{array}{l}\text { Penuangan } \\
\text { Bahan Baku }\end{array}$ & $\begin{array}{c}38 \\
\text { (sedang) }\end{array}$ & $\begin{array}{c}7 \\
\text { (medium) }\end{array}$ & & & $\begin{array}{c}47 \\
\text { (tinggi) }\end{array}$ & $\begin{array}{c}11 \\
\text { (sangat } \\
\text { tinggi) }\end{array}$ & $\begin{array}{l}\text { Penyusunan } \\
\text { Botol-botol } \\
\text { ke Tampah }\end{array}$ \\
\hline $\begin{array}{c}\text { Penuangan Isi } \\
\text { Dandang }\end{array}$ & $\begin{array}{c}35 \\
\text { (sedang) }\end{array}$ & $\begin{array}{c}8 \\
\text { (tinggi) }\end{array}$ & & & $\begin{array}{c}45 \\
\text { (tinggi) }\end{array}$ & $\begin{array}{c}10 \\
\text { (tinggi) }\end{array}$ & $\begin{array}{l}\text { Penakaran/ } \\
\text { Penimbangan } \\
\text { Isi Sugarwax }\end{array}$ \\
\hline & & & & & $\begin{array}{c}44 \\
\text { (sedang) }\end{array}$ & $\begin{array}{c}10 \\
\text { (tinggi) }\end{array}$ & $\begin{array}{c}\text { Pengambilan } \\
\text { Botol }\end{array}$ \\
\hline $\begin{array}{l}\text { Pengadukan } \\
\text { Bahan Baku }\end{array}$ & $\begin{array}{c}29 \\
\text { (sedang) }\end{array}$ & $\begin{array}{c}6 \\
\text { (medium) }\end{array}$ & & 13 & $\begin{array}{c}44 \\
\text { (sedang) }\end{array}$ & $\begin{array}{c}8 \\
\text { (tinggi) }\end{array}$ & $\begin{array}{c}\text { Pengisian } \\
\text { Sugarwax ke } \\
\text { Botol }\end{array}$ \\
\hline $\begin{array}{c}\text { Penurunan } \\
\text { Dandang dari }\end{array}$ & 29 & 3 & & & $\begin{array}{c}42 \\
\text { (sedang) }\end{array}$ & $\begin{array}{c}10 \\
\text { (tinggi) }\end{array}$ & $\begin{array}{c}\text { Pemberian } \\
\text { Label }\end{array}$ \\
\hline $\begin{array}{l}\text { Mesin Aduk } \\
\text { Pengangkatan } \\
\text { Dandang ke }\end{array}$ & 29 & (rendah) & & & $\begin{array}{c}41 \\
\text { (sedang) }\end{array}$ & $\begin{array}{c}9 \\
\text { (tinggi) }\end{array}$ & $\begin{array}{c}\text { Penyusunan } \\
\text { Botol ke } \\
\text { dalam Kotak } \\
\text { Kemasan }\end{array}$ \\
\hline Atas Kompor & (sedang) & (rendah) & & & $\begin{array}{c}37 \\
\text { (sedang) }\end{array}$ & $\begin{array}{c}5 \\
\text { (medium) }\end{array}$ & $\begin{array}{l}\text { Pemberian } \\
\text { Sticker }\end{array}$ \\
\hline
\end{tabular}

Dari pengumpulan dan pengolahan data kuesioner NBM, gambar bagian tubuh dengan warna merah adalah bagian tubuh yang mengalami keluhan sakit. Dari perbandingan ketiga tools di atas untuk mengetahui tingkat risiko ergonomi, dapat menunjukkan aktivitas yang memiliki risiko tertinggi yaitu aktivitas penyusunan botol-botol ke tampah dengan nilai WERA sebesar 47 dengan level risiko tinggi dan nilai REBA sebesar 11 dengan level risiko sangat tinggi yang menunjukkan bahwa aktivitas tersebut memerlukan implementasi perbaikan langsung. Keluhan muskuloskeletal berdasarkan kuesioner NBM dimana keluhan berupa sakit dan pegal pada bagian punggung terutama diakibatkan dari postur tubuh memutar (twist) dan membungkuk pada saat penyusunan botol-botol. Pada urutan tingkat risiko tertinggi selanjutnya yaitu pada aktivitas penakaran/ penimbangan isi sugarwax dengan nilai WERA sebesar 45 dengan level risiko tinggi dan nilai REBA sebesar 10 dengan level risiko tinggi. Urutan tingkat risiko tertinggi selanjutnya adalah aktivitas pengambilan botol dan pengisian sugarwax ke botol. Aktivitas dengan tingkat risiko tertinggi inilah yang perlu dilakukan implementasi perbaikan segera karena dapat membahayakan kesehatan dan keselamatan pekerja apabila tidak dilakukan perubahan dan perbaikan.

\section{Waktu Proses}

Pengukuran waktu proses digunakan sebagai parameter untuk mengetahui perubahan setelah dilakukannya implementasi, yaitu dengan perhitungan waktu baku. Setelah dilakukan pengambilan waktu siklus, dilakukan terlebih dahulu uji keseragaman, kenormalan, dan kecukupan data. Data yang telah teruji seragam, normal, dan cukup selanjutnya dilakukan perhitungan waktu baku. Hasil dari perhitungan waktu siklus (Ws), waktu normal (Wn), dan waktu baku (Wb) yang mempertimbangkan faktor penyesuaian $(p)$ dan kelonggaran (allowance) dapat dilihat pada Tabel 3 berikut.

Tabel 3. Perhitungan Waktu Proses

\begin{tabular}{clccccc}
\hline No. & \multicolumn{1}{c}{ Aktivitas } & $\begin{array}{c}\text { Ws } \\
\text { (detik) }\end{array}$ & $p$ & $\begin{array}{c}\text { Wn } \\
\text { (detik) }\end{array}$ & $\begin{array}{c}\text { Allowance } \\
(\boldsymbol{\%})\end{array}$ & $\begin{array}{c}\text { Wb } \\
\text { (detik) }\end{array}$ \\
\hline 1. & Pengisian Sugarwax ke Botol & 11,217 & 1,14 & 12,788 & 30,50 & $\mathbf{1 6 , 6 8 8}$ \\
2. & Penakaran Isi Sugarwax & 16,142 & 1,09 & 17,594 & 39,50 & $\mathbf{2 4 , 5 4 4}$ \\
3. & Penyusunan Botol-botol & 5,097 & 1,21 & 6,167 & 30,00 & $\mathbf{8 , 0 1 7}$ \\
4. & Pemberian Label & 4,368 & 1,25 & 5,459 & 35,50 & $\mathbf{7 , 3 9 7}$ \\
5. & Pemberian Sticker & 21,097 & 1,11 & 23,418 & 37,50 & $\mathbf{3 2 , 2 0 0}$ \\
6. & Penyusunan Botol ke dalam Kotak & 10,859 & 1,18 & 12,814 & 36,00 & $\mathbf{1 7 , 4 2 7}$ \\
\hline
\end{tabular}




\section{Perancangan Alat Bantu}

Perancangan alat bantu berdasarkan analisis terhadap keluhan subyektif pekerja dari kuisioner NBM. Alternatif desain dilakukan dengan membagikan kuesioner tertutup kepada pemilik dan pekerja di UKM Sugarwax. Hasilnya berupa alternatif bentuk sambungan meja berupa menyatu, dapat dilipat dan dapat disimpan; material meja berupa kayu lapis, besi dan akrilik; bentuk permukaan meja berupa bundar dan kombinasi; bentuk laci berupa tarik dan buka; mekanisme pemindahan meja dengan roda; warna meja berupa warna asli bahan dan pastel; material kursi berupa kayu lapis, besi, dan plastik (PP); mekanisme pemindahan kursi dengan roda dan tanpa roda; mekanisme ketinggian kursi berupa adjustable dan nonadjustable; kursi dengan dan tanpa lengan kursi; serta warna kursi berupa warna asli bahan, pastel, dan monokromatik.

Gambar dan keterangan setiap alternatif desain alat bantu meja kerja dapat dilihat pada Tabel 5, sedangkan gambar dan keterangan setiap alternatif desain alat bantu kursi dapat dilihat pada Tabel 6 .

Tabel 5. Alternatif Desain Alat Bantu Meja Kerja

Merupakan meja kerja dengan bentuk yang dapat
dilipat dan terbagi menjadi 2 bagian, yaitu bagian
kiri merupakan meja dengan permukaan yang
dapat diputar 360 derajat sebagai tempat untuk
meletakkan tampah tempat penyusunan botol.
Bagian kanan merupakan area meletakkan ember.
Diantara kedua bagian ini terdapat engsel
sehingga kotak tempat meletakkan ember dapat
dilipat ketika sedang tidak digunakan sehingaa
dapat menghemat ruang.


Tabel 6. Alternatif Desain Alat Bantu Kursi Kerja

No.
Alternatif

\section{Analytical Hierarcy Process (AHP)}

Setelah dihasilkan 3 (tiga) alternatif desain meja dan kursi kerja yang paling sesuai, tahap selanjutnya adalah pemilihan keputusan dengan menggunakan metode AHP. Tahap awal penggunaan AHP adalah menentukan tujuan utama ( $g o a l$ ) dan membuat stuktur hirarki dimulai dari tingkat paling atas dengan tujuan utama (goal) kemudian tingkat berikutnya berupa kriteria-kriteria pemilihan dan tingkat paling terakhir yaitu alternatif-alternatif alat bantu. Seluruh nilai perbandingan berpasangan pada matriks kriteria yang diberikan pada perhitungan AHP telah konsisten, ditunjukkan oleh hasil perhitungan nilai rasio konsistensi (CR) untuk tiap-tiap nilai perbandingan berpasangan pada perhitungan AHP meja kerja dan kursi kerja yaitu nilai CR $<0,10$. Hasil perhitungan AHP alat bantu berupa meja dan kursi kerja dapat dilihat pada Tabel 7 dan Tabel 8 berikut ini.

Tabel 7. Bobot Keseluruhan AHP Meja Kerja

\begin{tabular}{|c|c|c|c|c|c|c|c|}
\hline \multirow{2}{*}{ Kriteria } & \multirow{2}{*}{$\begin{array}{c}\text { Bobot } \\
\text { Kriteria }\end{array}$} & \multicolumn{3}{|c|}{ Bobot Alternatif } & \multicolumn{3}{|c|}{ Bobot Keseluruhan } \\
\hline & & Alt 1 & Alt 2 & Alt 3 & Alt 1 & Alt 2 & Alt 3 \\
\hline Fungsional & 0,34713 & 0,57377 & 0,30190 & 0,12433 & 0,19917 & 0,10480 & 0,04316 \\
\hline $\begin{array}{l}\text { Kemudahan } \\
\text { Penggunaan }\end{array}$ & 0,23245 & 0,10225 & 0,68996 & 0,20779 & 0,02377 & 0,16038 & 0,04830 \\
\hline $\begin{array}{c}\text { Kenyamanan } \\
\text { Penggunaan }\end{array}$ & 0,28084 & 0,31964 & 0,50109 & 0,17927 & 0,08977 & 0,14073 & 0,05034 \\
\hline Material & 0,09769 & 0,08742 & 0,27118 & 0,64140 & 0,00854 & 0,02649 & 0,06266 \\
\hline Desain & 0,04190 & 0,19696 & 0,23745 & 0,56559 & 0,00825 & 0,00995 & 0,02370 \\
\hline \multicolumn{5}{|c|}{ JUMLAH } & $\mathbf{0 , 3 2 9 5 0}$ & 0,44234 & 0,22816 \\
\hline
\end{tabular}

Tabel 8. Bobot Keseluruhan AHP Kursi Kerja

\begin{tabular}{cccccccc}
\hline \multirow{2}{*}{ Kriteria } & Bobot & \multicolumn{3}{c}{ Bobot Alternatif } & \multicolumn{3}{c}{ Bobot Keseluruhan } \\
\cline { 3 - 8 } & Kriteria & Alt 1 & Alt 2 & Alt 3 & Alt 1 & Alt 2 & Alt 3 \\
\hline $\begin{array}{c}\text { Material } \\
\text { Kenyamanan }\end{array}$ & 0,19492 & 0,53475 & 0,08905 & 0,37620 & 0,10423 & 0,01736 & 0,07333 \\
Penggunaan & 0,48396 & 0,40118 & 0,48193 & 0,11689 & 0,19416 & 0,23323 & 0,05657 \\
Fitur & 0,25561 & 0,13674 & 0,20864 & 0,65462 & 0,03495 & 0,05333 & 0,16733 \\
Desain & 0,06551 & 0,66967 & 0,22422 & 0,10611 & 0,04387 & 0,01469 & 0,00695 \\
\hline \multicolumn{3}{c}{ JUMLAH } & & & $\mathbf{0 , 3 7 7 2 1}$ & $\mathbf{0 , 3 1 8 6 1}$ & $\mathbf{0 , 3 0 4 1 8}$ \\
\hline
\end{tabular}


Pada tabel hasil perhitungan bobot keseluruhan yang didapatkan dengan menjumlahkan bobot dari masingmasing kriteria untuk setiap alternatif, maka akan dipilih nilai bobot keseluruhan dengan nilai tertinggi untuk diambil sebagai alternatif yang terpilih untuk dilakukan pengimplementasian perbaikan selanjutnya. Berdasarkan Tabel 7 dan Tabel 8 di atas, maka didapatkan alternatif desain meja 2 dengan bobot terbesar yaitu 0,44234 atau 44,23\% dan alternatif desain kursi 1 dengan bobot terbesar yaitu 0,37721 atau 37,72\% dan akan dikembangkan.

\section{Dimensi Produk}

Penentuan dimensi alat bantu kerja akan didasarkan pada data antropometri wanita Indonesia [4]. Berdasarkan hasil alternatif desain yang telah terpilih pada pemilihan dengan menggunakan metode AHP, maka desain alat bantu meja kerja dan kursi kerja beserta dimensinya (dalam milimeter) dapat dilihat pada Gambar 1 berikut.
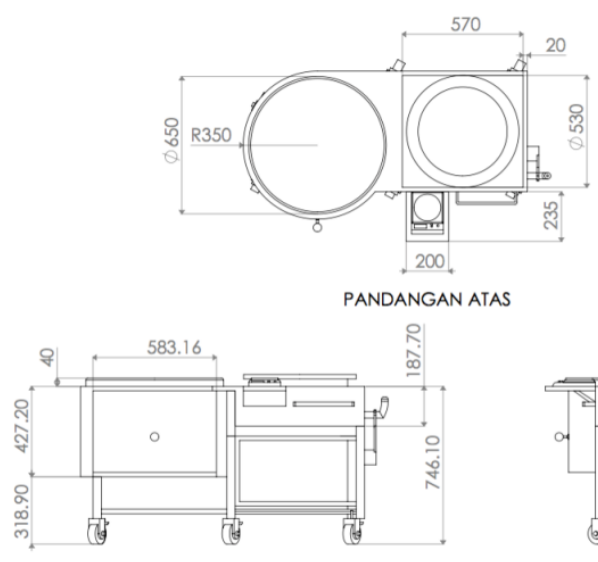

PANDANGAN DEPAN

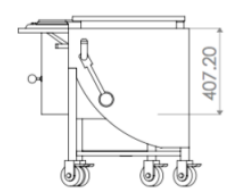

PANDANGAN SAMPING KANAN

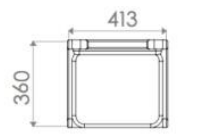

PANDANGAN ATAS
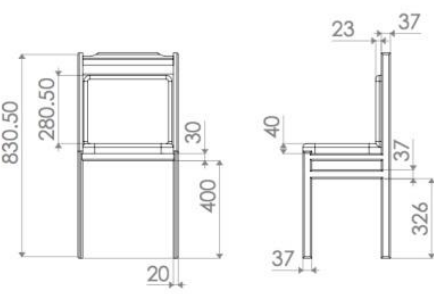

PANDANGAN DEPAN PANDANGAN SAMPING KANAN

Gambar 1. Desain Meja Kerja dan Kursi Kerja

Tabel 9. Dimensi Meja Kerja

\begin{tabular}{|c|c|c|c|c|c|c|}
\hline No. & $\begin{array}{c}\text { Dimensi yang } \\
\text { Digunakan }\end{array}$ & Fungsi & Persentil & $\begin{array}{c}\text { Ukuran } \\
(\mathrm{cm})\end{array}$ & $\begin{array}{c}\text { Penyesuaian } \\
(\mathrm{cm})\end{array}$ & $\begin{array}{l}\text { Total } \\
(\mathrm{cm})\end{array}$ \\
\hline & Tinggi Siku dan & Tinggi Meja & & & & \\
\hline 1. & $\begin{array}{l}\text { Tinggi Popliteal } \\
\text { (Lipat Lutut) }\end{array}$ & $\begin{array}{l}\text { Bagian Luar } \\
\text { dari Lantai }\end{array}$ & $95 \%$ & 74,61 & - & 74,61 \\
\hline 2. & Tinggi Lutut & $\begin{array}{c}\text { Tinggi Meja } \\
\text { Bagian Dalam } \\
\text { dari Lantai }\end{array}$ & $95 \%$ & 53,84 & $\begin{array}{c}5 \% \\
(2,00 \mathrm{~cm})\end{array}$ & 55,84 \\
\hline 3. & $\begin{array}{c}\text { Panjang Lengan } \\
\text { Bawah }\end{array}$ & $\begin{array}{l}\text { Kedalaman } \\
\text { Laci }\end{array}$ & $5 \%$ & 38,72 & $\begin{array}{c}10 \% \\
(4,00 \mathrm{~cm})\end{array}$ & 42,72 \\
\hline 4. & Diameter Tampah & Panjang Meja & - & 129,00 & - & 129,00 \\
\hline 5. & Diameter Ember & Lebar Meja & - & 65,00 & $\begin{array}{c}8 \% \\
(5,00 \mathrm{~cm})\end{array}$ & 70,00 \\
\hline 6. & Tinggi Ember & Tinggi Kotak & - & 18,77 & - & 18,77 \\
\hline
\end{tabular}


Tabel 10. Dimensi Kursi Kerja

\begin{tabular}{|c|c|c|c|c|c|c|}
\hline No. & $\begin{array}{l}\text { Dimensi yang } \\
\text { Digunakan }\end{array}$ & Fungsi & Persentil & $\begin{array}{c}\text { Ukuran } \\
(\mathrm{cm})\end{array}$ & $\begin{array}{l}\text { Penyesuaian } \\
(\mathrm{cm})\end{array}$ & $\begin{array}{l}\text { Total } \\
(\mathrm{cm})\end{array}$ \\
\hline 1. & $\begin{array}{l}\text { Tinggi Popliteal } \\
\text { (Lipat Lutut) }\end{array}$ & $\begin{array}{l}\text { Tinggi Kaki } \\
\text { Kursi }\end{array}$ & $95 \%$ & 40,00 & $\begin{array}{c}12,5 \% \\
(5,00 \mathrm{~cm})\end{array}$ & 45,00 \\
\hline 2. & $\begin{array}{c}\text { Jarak Popliteal } \\
\text { ke Pantat }\end{array}$ & $\begin{array}{c}\text { Panjang } \\
\text { Alas Duduk }\end{array}$ & $5 \%$ & 36,00 & - & 36,00 \\
\hline 3. & Lebar Panggul & $\begin{array}{l}\text { Lebar Kursi } \\
\text { (Sandaran) }\end{array}$ & $95 \%$ & 37,30 & - & 37,30 \\
\hline 4. & Lebar Sisi Bahu & $\begin{array}{l}\text { Lebar Luar } \\
\text { Kursi }\end{array}$ & $95 \%$ & 41,30 & - & 41,30 \\
\hline 5. & $\begin{array}{c}\text { Setengah } \\
\text { Tinggi Bahu } \\
\text { pada Posisi } \\
\text { Duduk }\end{array}$ & $\begin{array}{l}\text { Tinggi } \\
\text { Sandaran }\end{array}$ & $95 \%$ & 30,55 & - & 30,55 \\
\hline 6. & $\begin{array}{c}\text { Panjang } \\
\text { Telapak Tangan }\end{array}$ & $\begin{array}{l}\text { Lebar } \\
\text { Handle } \\
\text { Kursi }\end{array}$ & $5 \%$ & 7,00 & - & 7,00 \\
\hline
\end{tabular}

Rancangan alat bantu berupa meja dan kursi kerja yang telah diimplementasikan pada UKM Sugarwax dapat dilihat pada Gambar 2 berikut ini.
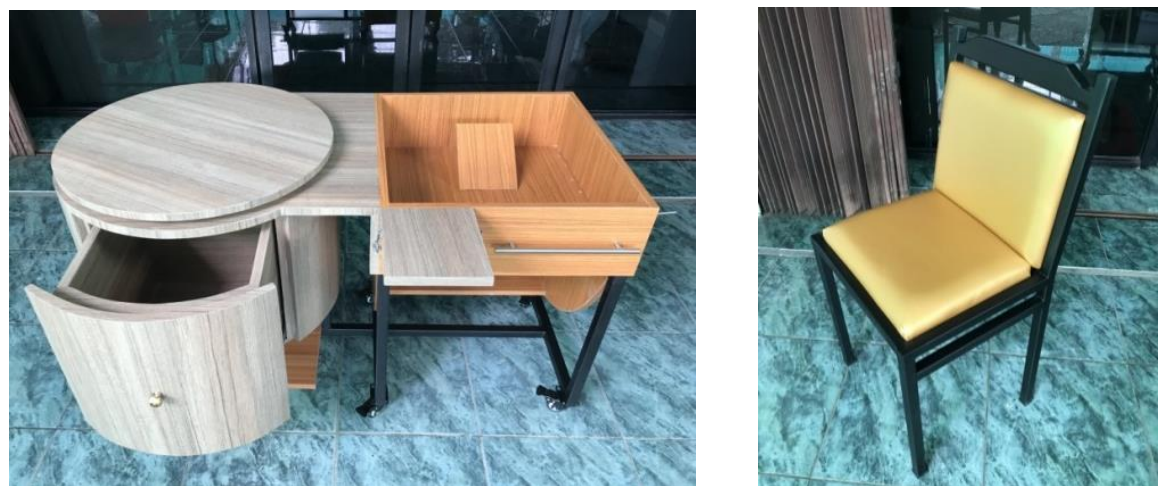

Gambar 2. Meja dan Kursi Kerja

\section{Perbandingan Hasil Kuesioner NBM, WERA dan REBA Setelah Implementasi}

Implementasi dari prototipe alternatif terpilih dilakukan dengan operator yang sama dengan sebelum penggunaan alat bantu. Berikutnya dilakukan perhitungan risiko ergonomi dengan menggunakan metode WERA dan REBA serta mengetahui keluhan fisik pekerja berdasarkan kuesioner NBM. Perbandingan dari ketiga metode ini dimanfaatkan untuk menganalisis perubahan yang terjadi dan mengetahui perbandingan yang dihasilkan antara level risiko ergonomi sebelum dan setelah implementasi. Perbandingan melalui WERA, REBA, dan Kuesioner Nordic Body Map setelah implementasi dapat dilihat pada Tabel 12. 
Tabel 12. Perbandingan Aktivitas Melalui WERA, REBA, dan Kuesioner Nordic Body Map Setelah Implementasi

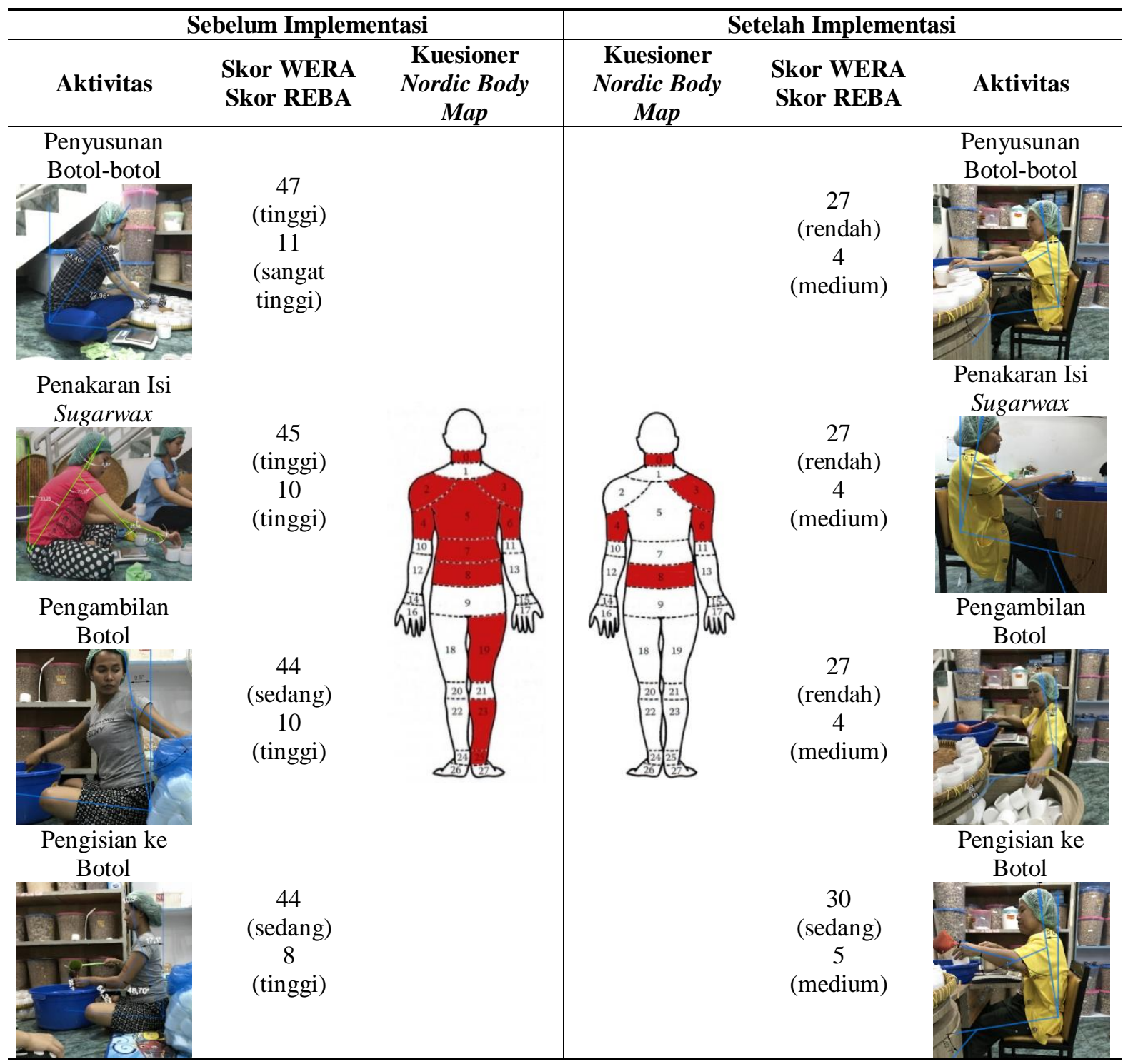

Dari hasil analisis yang dapat dilihat pada Tabel 12 di atas, dari hasil pengukuran dengan menggunakan metode WERA, keseluruhan aktivitas dengan level risiko tertinggi yang dilakukan perbaikan dengan rancangan alat bantu mengalami penurunan yang cukup besar. Sebelum dilakukan untuk aktivitas penyusunan botol ke tampah memiliki tingkat risiko WERA tinggi yaitu dengan skor 47 artinya pekerjaan yang diamati tidak dapat diterima dan perlu dilakukan perbaikan segera. Setelah dilakukan implementasi perbaikan rancangan alat bantu menurunkan level risiko WERA dari level tinggi menjadi level rendah dengan skor 27 yang artinya pekerjaan yang diamati sudah baik dan dapat diterima.

Dari hasil pengukuran dengan menggunakan metode REBA, keseluruhan aktivitas dengan level risiko tertinggi yang dilakukan perbaikan mengalami penurunan yang cukup besar. Sebelum dilakukan perbaikan aktivitas penyusunan botol ke tampah memiliki tingkat risiko REBA sangat tinggi yaitu dengan skor 11 yang artinya pekerjaan yang diamati perlu investigasi lebih lanjut dan diperlukan perbaikan langsung. Setelah dilakukan implementasi perbaikan menurunkan level risiko REBA dari level sangat tinggi menjadi level medium dengan skor 4 artinya pekerjaan yang diamati membutuhkan investigasi lanjut dan perbaikan.

Hal ini menunjukkan bahwa perancangan ulang stasiun dan alat bantu kerja dengan prinsip ergonomi dapat memperbaiki postur tubuh pekerja pada aktivitas pengemasan yang memiliki risiko tinggi, sehingga menurunkan level risiko ergonomi. 


\section{Pengukuran Waktu Proses Setelah Implementasi}

Berikut ini merupakan perbandingan perhitungan waktu baku sebelum dan setelah dilakukannya implementasi untuk aktivitas-aktivitas yang dilakukan perbaikan yang dapat dilihat pada Tabel 13.

Tabel 13. Perbandingan Waktu Sebelum dan Sesudah Implementasi

\begin{tabular}{cccc}
\hline \multicolumn{4}{c}{ Total Waktu Baku } \\
\hline Sebelum & Setelah & Selisih & Persentase \\
Implementasi & Implementasi & 20,118 detik & $40,85 \%$ \\
49,249 detik & 29,131 detik &
\end{tabular}

Perhitungan output standar per jamnya untuk masing-masing pekerja pada Tabel 14 berikut.

Tabel 14. Perbandingan Output per Pekerja

\begin{tabular}{cccc}
\hline \multicolumn{2}{c}{ Sebelum Implementasi } & \multicolumn{2}{c}{ Setelah Implementasi } \\
\hline Waktu Baku & Output Standar & Waktu Baku & Output Standar \\
106,273 detik & $33 \mathrm{buah} / \mathrm{jam}$ & $86,155 \mathrm{detik}$ & $41 \mathrm{buah} / \mathrm{jam}$ \\
\hline
\end{tabular}

Adanya penurunan total waktu baku ini menyebabkan output standar mengalami peningkatan sebanyak 8 buah per jamnya. Hal ini menunjukkan bahwa dalam satu jam, seorang pekerja dapat menghasilkan 41 buah produk sugarwax yang telah selesai dikemas dan siap kirim. Maka, dengan adanya perbaikan terhadap stasiun dan alat bantu kerja dengan konsep ergonomi dapat menurunkan waktu proses dari aktivitas pengemasan sehingga meningkatkan produktivitas.

\section{Kesimpulan dan Saran}

Berdasarkan penelitian dan analisis yang telah dilakukan, maka dapat ditarik kesimpulan bahwa setelah dilakukan analisis terhadap hasil kuesioner NBM ditemukan bahwa pekerja mengalami keluhan-keluhan fisik terparah pada aktivitas pengemasan yang didukung dengan analisis WERA dan REBA. Level risiko WERA tertinggi yaitu skor 47 (tinggi) dan skor REBA 11 (sangat tinggi) yang artinya diperlukan implementasi perbaikan langsung. Setelah dilakukan proses perancangan didapatkan rancangan alternatif dan dilakukan implementasi alat bantu. Hasil implementasi terhadap meja dan kursi kerja didapatkan hasil sebagai berikut; skor WERA tertinggi menurun dari skor 47 (tinggi) menjadi 27 (rendah) dan skor REBA tertinggi menurun dari skor 11 (sangat tinggi) menjadi 5 (medium); penurunan sebesar 100\% terhadap keluhan sakit pada pinggang, bahu kiri, punggung, paha kanan, betis kanan, dan pergelangan kaki kanan; dan waktu baku untuk aktivitas yang dilakukan implementasi mengalami penurunan sebesar $40,85 \%$. Dengan demikian seorang pekerja dapat menghasilkan 41 produk yang telah siap kirim per jamnya, meningkat sebanyak 8 buah produk per jam dari produktivitas sebelumnya 33 buah produk per jam. Hal ini menunjukkan bahwa perancangan ulang stasiun dan alat bantu kerja dengan prinsip ergonomi dapat memperbaiki postur tubuh pekerja, menurunkan level risiko ergonomi dengan perbaikan stasiun kerja, dan meningkatkan output standar. 


\section{DAFTAR PUSTAKA}

[1] Kementrian Koperasi dan Usaha Kecil Menengah, "Perkembangan Data Usaha Mikro, Kecil, Menengah (UMKM) dan Usaha Besar (UB) Tahun 2012-2013", diakses dari http://www.depkop.go.id/ pada tanggal 12 Agustus 2017 pukul 18.01 WIB.

[2] Kementrian Dalam Negeri, "Undang-Undang Republik Indonesia Nomor 20 Tahun 2008 Tentang Usaha Mikro, Kecil, dan Menengah", diakses dari http://www.kemendagri.go.id/ pada tanggal 12 Agustus 2017 pukul 19.30 WIB.

[3] Shinde, G. V. dan V. S. Jadhav, 2012, Ergonomic Analysis of an Assembly Workstation to Identify Time Consuming and Fatigue Causing Factors Using Application of Motion Study, Int. J. Eng. Technol., vol. 4, no. 4, pp. 220-227.

[4] Antropometri Indonesia,"Data Antropometri Indonesia",diakses dari http://www.antropometri.ie.its.ac.id/ pada tanggal 27 Oktober 2017 pukul 19.30 WIB

[5] IEA (International Ergonomic Association), diaskses dari https://www.iea.cc/whats/index.html, pada tanggal 8 Oktober 2018 pukul 14.50 WIB.

[6] ILO (International Labour Office), 2010, Ergonomic Checkpoints: Practical and Easy to Implement Solutions for Improving Safety, Health and Working Conditions Second Edition, Geneva: International Labour Office.

[7] Singh, Surabhi, Ahlawat S, Pandya S, dan Prafull B., 2013, Anthropometric Measurements and Body Composition Parameters of Farm Women in North Gujarat, Journal of Ergonomics 3: 114.

Stanton, Neville, Alan Hedge, Karel Brookhuis, Eduardo Salas, dan Hal Hendrick, 2005, Handbook of Human Factors and Ergonomics Methods, New York: CRC Press.[8] Kourinka I, Jonsson B, Kilbom A, Vinterberg H, Biering-Sørensen F, Andersson G, Jørgensen K, 1987, Standardised Nordic questionnaires for the analysis of musculoskeletal symptoms, Applied Ergonomics, vol. 18, issue 3 (1987) pp. 233-237

[9] Abd Rahman, M. N. Asrull, Abdul Rani, M. R. ebi, dan Rohani, J. M. ohd, 2011, WERA: an Observational Tool Develop to Investigate The Physical Risk Factor Associated with WMSDs, Journal of Human Ergology (Tokyo), 40(1-2), 19-36.

[10] Hignett, S. dan McAtamney L., 2000, Rapid Entire Body Assessment (REBA), Applied Ergonomics, vol. 31, no. 2. pp. 201-205.

[11] Saaty, T.L. dan L.G. Vargas, 2012, Models, methods, concepts \& applications of the analytic hierarchy process, $2^{\text {nd }}$ edition, Springer, New York, . 